\title{
Eucalyptus grandis W. Hill ex Maiden Leaf and Flower Extracts Lack Antibacterial activity and are Non-toxic in vitro
}

\author{
Getmore Chikowe', Lindiwe Mpala', Ian Edwin Cock ${ }^{1,2, *}$ \\ 'School of Environment and Science, Nathan Campus, Griffith University, Nathan, Brisbane, Queensland-4111, AUSTRALIA. \\ 2Environmental Futures Research Institute, Griffith University, Nathan, Brisbane, Queensland-4111, AUSTRALIA.
}

\begin{abstract}
Introduction: Closely related plant species often share similar secondary metabolites and bioactivities and are therefore good targets for bioactivity testing when one or more species within a genus are known to possess therapeutic properties. The genus Eucalyptus has a long history of medicinal usage by the first Australians. Many species are known to have therapeutic properties, several species of which have well established antibacterial bioactivities. Methods: The ability of Eucalyptus grandis leaf and flower extracts to inhibit the growth of a panel of bacterial and fungal pathogens was investigated by disc diffusion assay. Toxicity was examined using the Artemia franciscana nauplii bioassay. Results: E. grandis leaf and flower methanolic and aqueous extracts were completely ineffective at inhibiting the growth of gram-positive and gram-negative panels of bacteria, as well as fungi. The extracts were nontoxic in the Artemia nauplii bioassay following $24 \mathrm{hr}$ exposure. Conclusion: Despite the taxonomic relationship to several bioactive Eucalyptus spp., E. grandis leaf and flower extracts
\end{abstract}

were completely ineffective bacterial and fungal growth inhibitors. However, these extracts may have other therapeutic properties and testing against protozoa, virus and tumour cells is required.

Key words: Myrtaceae, Rose gum, Antibacterial activity, Australian plant, Traditional medicine, Medicinal plants, Toxicity.

\section{Correspondence:}

Dr. Ian Edwin Cock

${ }^{1}$ School of Environment and Science, Nathan Campus, Griffith University, Nathan, Brisbane, Queensland-4111, AUSTRALIA.

${ }^{2}$ Environmental Futures Research Institute, Griffith University, Nathan, Brisbane, Queensland-4111, AUSTRALIA.

Phone no: +61737357637

E-mail: i.cock@griffith.edu.au

DOI: $10.5530 /$ pc.2020.1.5

\section{INTRODUCTION}

Traditional plant derived medicines have been used in most parts of the world for a variety of therapeutic purposes, including fighting microbial disease. Indeed, the ability of plant extracts to block the growth of pathogenic bacteria has become a focus of substantial recent study. ${ }^{1-5}$ Much of the research into traditional medicinal plant use has focused on Asian, ${ }^{6-8}$ African, ${ }^{9-11}$ Middle Eastern ${ }^{12-14}$ and South American ${ }^{15}$ plants. However, despite the potential of plants to provide us with useful pharmaceutical agents, the field is still relatively poorly studied. Only an estimated $5-10 \%$ of the approximately 300,000-500,000 plant species worldwide have been screened for one or more bioactivities. ${ }^{9}$ With so many plant species yet to be tested, it is essential that plant selection processes narrow the field. The main selection criteria currently used is to select plants on the basis of ethnobotanical usage as traditional medicines. Another important selection method is to examine plants related to species for which medicinal potential is well established. Many plant secondary metabolites are regarded as family, genus or species specific and investigation of species closely related to those used as traditional medicines may lead to natural therapeutic discoveries. ${ }^{16}$

The development of new antibiotic therapies is particularly urgent. The recent establishment of bacterial pathogens that are either extremely (XDR) or totally resistant (TDR) to common clinically used antibiotics ${ }^{17}$ has resulted in the need to develop new and effective antibiotic chemotherapies. There are now limited therapeutic options for many diseases caused by bacterial pathogens and the situation is expected to worsen in the future as bacteria exchange resistance genes. Indeed, the development of alternative antibacterial treatment modalities has become crucial and is considered by the World Health Organisation (WHO) to be one of the most serious challenges facing medical science. ${ }^{18}$ For a number of reasons reviewed elsewhere, ${ }^{17}$ it is unlikely that the previous methods of antibiotic discovery/development will be as successful in the future and new treatment modalities are urgently required. Traditional medicines and herbal remedies have great potential for antimicrobial drug development and there has recently been a substantial increase in interest in this field. ${ }^{19,20}$

The first Australians had well-developed medicinal systems and understood the therapeutic properties of a wide variety of Australian plants and how to use them effectively. ${ }^{16}$ Despite this, relatively few studies have rigorously examined the antibacterial activity of Australian native plants, although there has recently been a substantial increase in interest in this field. ${ }^{21-24}$ The genus Eucalyptus (family Myrtaceae) consists of more than 700 species of trees and shrubs, with the majority native to Australia. ${ }^{25}$ Eucalyptus grandis W. Hill. ex Maiden (commonly known as rose gum or flooded gum) is an endemic Australian tree (Figure 1a) that grows in coastal regions of Eastern Australia from the Sydney region northwards to central Queensland. It is a large tree and grows to approximately 50 metres, although some specimens can exceed 80 metres high. Its long straight trunk is valued by the timber and pulp industries and extensive plantations have been established internationally, particularly in South Africa and Brazil. The glossy green leaves (10-16 cm long by $2-3 \mathrm{~cm}$ wide) are lanceolate and paler on the undersides (Figure $1 \mathrm{~b}$ ). White flowers (Figure 1b) appear in mid-autumn to late winter and develop into small ( $6 \mathrm{~mm}$ by $5 \mathrm{~mm}$ ) cone shaped gumnuts with protruding valves (Figure 1c).

Many Eucalyptus spp., were used by the first Australians for their antiseptic properties ${ }^{16,26}$ and the efficacy has been verified for several species in laboratory studies. ${ }^{27}$ In contrast, there is less evidence that E. grandis was used medicinally by the first Australians and relatively few studies have tested the antibiotic properties of this species. A recent study reported potent growth inhibitory activity for essential oils produced from E. grandis leaves against a broad panel of pathogenic bacteria, including many of the same species tested in our study. ${ }^{28}$ However, that study tested high concentration of essential oils and reported MIC values of $\geq 10 \mathrm{mg} / \mathrm{mL}$ against many of the bacterial species tested. It is noteworthy that these MICs would be classified as inactive in 
many test systems. Furthermore, there may be doubts about the results of this study as the MIC values reported for the standard drug ampicillin against these bacteria was similar to that reported for the essential oils (i.e. $\geq 10 \mathrm{mg} / \mathrm{mL}$ ), even against ampicillin sensitive bacterial strains. We were unable to find any studies examining the antibacterial activity of solvent extractions.

The phytochemical composition of E. grandis is also relatively poorly studied. However, one recent study identified $\beta$-sitosterol (Figure 1d), syringaldehyde (Figure 1e), catechin (Figure 1f), proanthocyanidin dimer (Figure 1g), ellagic acid (Figure $1 \mathrm{~h}$ ) and ellagic acli-O-pentoside (Figure 1i) in E. grandis wood. ${ }^{29}$ Phytochemical evaluations of the other parts of this species are less extensive and much further work is required. Many of these compounds have been reported to have potent antibacterial activity ${ }^{30}$ and may therefore contribute to the antibacterial properties of E. grandis. This study was undertaken to screen E. grandis leaf and flower extracts for the ability to inhibit the growth of a panel of gram-positive and gram-negative bacterial pathogens and three fungi.

\section{MATERIALS AND METHODS}

Plant material

Collection of plant material and extraction

Eucalyptus grandis W. Hill ex Maiden leaves and flowers were obtained from and identified by Philip Cameron, senior botanic officer, Mt Cootha Botanical Gardens, Brisbane, Australia. The harvested leaves and flowers were washed in deionised water and processed within $4 \mathrm{hr}$ of collection. The leaves were dried in a Sunbeam food dehydrator and the dried material was ground to a coarse powder. Individual $1 \mathrm{~g}$ masses of the dried plant material was extracted extensively in $50 \mathrm{~mL}$ methanol (Ajax, AR grade) or deionised water for $24 \mathrm{hr}$ at $4^{\circ} \mathrm{C}$ with gentle shaking. The extract was filtered through filter paper (Whatman No. 54) under vacuum followed by drying by rotary evaporation. The resultant pellet was dissolved in $5 \mathrm{~mL}$ deionised water. The extract was passed through $0.22 \mu \mathrm{m}$ filter (Sarstedt) and stored at $4^{\circ} \mathrm{C}$.

\section{Qualitative phytochemical studies}

Phytochemical analysis of the E. grandis leaf and flower extracts for the presence of saponins, phenolic compounds, flavonoids, phytosteroids, triterpenoids, cardiac glycosides, anthraquinones, tannins and alkaloids was conducted by standard assays. ${ }^{31-33}$

\section{Antibacterial screening Test microorganisms}

All media was purchased from Oxoid Ltd., Australia. The reference strains of Escherichia coli (ATCC157293), Klebsiella pneumoniae (ATCC31488), Proteus mirabilis (ATCC21721) and Streptococcus pyogenes (ATCC19615) were purchased from American Tissue Culture Collection (ATCC), USA. Clinical isolate microbial strains of Aeromonas hydrophilia, Alcaligenes feacalis, Aspergillus niger, Bacillus cereus, Candida albicans, Citrobacter freundii, Pseudomonas fluorescens, Saccromyces cerviseae, Salmonella newport, Serratia marcescens, Shigella sonneii, Staphylococcus aureus and Staphylococcus epidermidis strains were obtained from Ms Michelle Mendell and Ms Jane Gifkins, Griffith University. All bacterial stock cultures were subcultured and maintained in nutrient broth at $4^{\circ} \mathrm{C}$. The fungal strains were cultured in Sabourand broth (Oxoid, Australia).

\section{Evaluation of antimicrobial activity}

Antimicrobial activity of the E. grandis leaf and flower extracts was determined using a modified disc diffusion assay. ${ }^{34-36}$ Briefly, $100 \mu \mathrm{L}$ of the each microbial suspension in $\log$ phase was spread onto individual nutrient agar plates (or Sabour and agar for the fungal strains) and the extracts were tested for antimicrobial activity using $6 \mathrm{~mm}$ sterilised filter paper discs. The discs were each infused with $10 \mu \mathrm{L}$ of the individual plant extract, allowed to dry and placed onto the inoculated plates. The plates were allowed to stand at $4^{\circ} \mathrm{C}$ for $2 \mathrm{hr}$ before incubation at $37^{\circ} \mathrm{C}$ for $24 \mathrm{hr}$. The diameters of the zones of inhibition (ZOIs) were measured to the closest whole millimetre. Each assay was performed three times in triplicate $(n=9)$. Mean values $( \pm$ SEM) are reported in this study. Standard discs of ampicillin $(10 \mu \mathrm{g})$, chloramphenicol $(10 \mu \mathrm{g})$ and nystatin $(100 \mu \mathrm{g})$ were obtained from Oxoid, Australia and were used as positive controls to compare antibacterial and antifungal activity. Filter discs infused with $10 \mu \mathrm{L}$ of distilled water were used as a negative control.

\section{Artemia franciscana nauplii toxicity screening}

Toxicity was tested using an adapted Artemia franciscana nauplii lethality assay. ${ }^{37-39}$ Briefly, A. franciscana nauplii were incubated in the presence of the extracts, reference toxin ( $1 \mathrm{mg} / \mathrm{mL}$ potassium dichromate) or artificial seawater (negative control) at $25 \pm 1^{\circ} \mathrm{C}$ under artificial light. All treatments were performed three times in triplicate $(n=9)$. The number of dead were counted in each well at $24 \mathrm{hr}, 48 \mathrm{hr}$ and $72 \mathrm{hr}$. At the completion of the $72 \mathrm{hr}$ exposure period, the remaining live nauplii were sacrificed and the total number of nauplii in each well were counted and used to calculate the $\%$ mortality per well. $\mathrm{LC}_{50}$ values were calculated for each treatment using probit analysis.

\section{Statistical analysis}

Data are expressed as the mean \pm SEM of three independent experiments with internal triplicates $(n=9)$. One-way ANOVA was used to calculate statistical significance between control and treated groups, with a $P$ value $<0.01$ considered to be statistically significant.

\section{RESULTS}

\section{Liquid extraction yields and qualitative phytochemical screening}

Extraction of $1 \mathrm{~g}$ of dried and powdered E. grandis leaves and flowers with methanol and water yielded 242 (aqueous leaf extract) to $348 \mathrm{mg}$ (methanolic flower extract) of extracted material respectively (Table 1). Methanol was a better extractant, resulting in higher yield of extracted material compared to water. Additionally, the flowers had higher extraction yields than the leaf extracts. The extracts were resuspended in $10 \mathrm{~mL}$ of deionised water (containing $1 \% \mathrm{DMSO}$ ), resulting in the extract concentrations shown in Table 1. Qualitative phytochemical studies showed that both leaf extracts had similar phytochemical profiles. Both contained high levels of phenolic compounds and flavonoids, as well as moderate levels of saponins and low levels of triterpenoids. The flower extracts also had similar phytochemical profiles to the leaf extracts.

\section{Antimicrobial activity}

To determine the growth inhibitory activity of the E. grandis leaf and flower extracts, aliquots $(10 \mu \mathrm{L})$ of each extract were screened in the disc diffusion assay. The E. grandis leaf and flower extracts were ineffective at inhibiting the growth of all gram-negative (Figure 2) and gram positive (Figure 3) bacterial species tested. In contrast, both positive control antibiotics (ampicillin and chloramphenicol) were effective growth inhibitors, with ZOI's of up to $14.3 \mathrm{~mm}$ (chloramphenicol against E. coli). We were therefore unable to determine the MIC values for any extract as they were completely ineffective at all concentrations tested. Similarly, all of the extracts were ineffective at inhibiting the growth of the three fungal species screened in this study (Figure 4). 


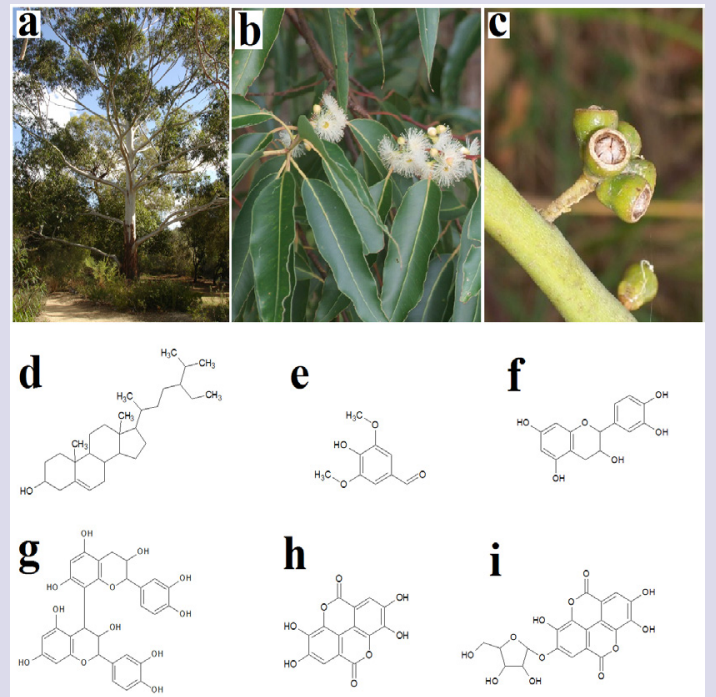

Figure 1: E. grandis (a) whole plant, (b) leaves and flowers, (c) fruit and some compounds identified in E. grandis: (d) $\beta$-sitosterol, (e) syringaldehyde, (f) catechin, (g) proanthocyanidin dimer, (h) ellagic acid and (i) ellagic acli-O-pentoside. ${ }^{29}$

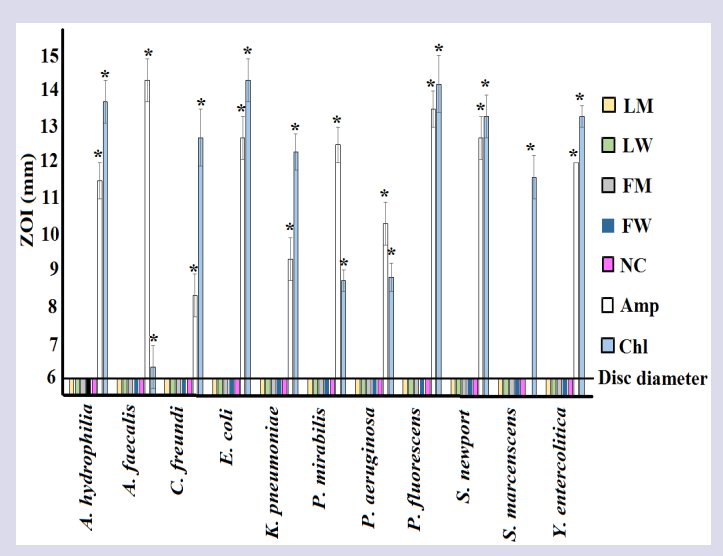

Figure 2: Growth inhibitory activity of $E$. grandis leaf and flower extracts and reference antibiotics against gram-negative bacterial species measured as ZOls $(\mathrm{mm}) \pm \mathrm{SEM}$. $\mathrm{L}=$ leaf; $\mathrm{F}=$ fruit; $\mathrm{M}=$ methanolic extract; $\mathrm{W}=$ aqueous extract; $\mathrm{Amp}=$ ampicillin $(10 \mu \mathrm{g}) ; \mathrm{Chl}=$ chloramphenicol $(10 \mu \mathrm{g}) ; \mathrm{NC}=$ negative control. All assays were completed three times, each with internal triplicates $(n=9)$ and the results are expressed as mean zones of inhibition $(\mathrm{mm}) \pm$ SEM.

\section{Quantification of Toxicity}

The toxicity of the E. grandis leaf and flower extracts was initially tested at $1000 \mu \mathrm{g} / \mathrm{mL}$ in the A. franciscana nauplii bioassay (Figure 5). The mortality in the presence of all extracts was substantially $<1000 \mu \mathrm{g} / \mathrm{mL}$ at $24 \mathrm{~h}$ and thus all extracts were deemed to be non-toxic. Extracts with $24 \mathrm{~h}$ LC $_{50}$ values $>1000 \mu \mathrm{g} / \mathrm{mL}$ have previously been defined as non-toxic. ${ }^{39} \mathrm{In}$ contrast, the potassium dichromate positive control induced substantial mortality within $4 \mathrm{hr}$ (results not shown), with $100 \%$ mortality induction seen by $24 \mathrm{hr}$. The mortality increased following exposure to the E. grandis leaf extracts at $48 \mathrm{hr}$ and was further increased following $72 \mathrm{hr}$ exposure.

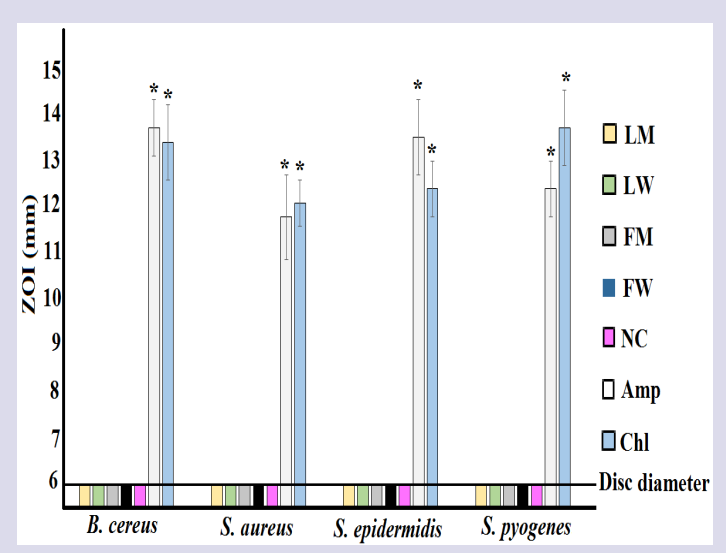

Figure 3: Growth inhibitory activity of $E$. grandis leaf extracts and reference antibiotics against gram-positive bacterial species measured as ZOIs $(\mathrm{mm}) \pm \mathrm{SEM}$. $\mathrm{L}=$ leaf; $\mathrm{F}=$ fruit; $\mathrm{M}=$ methanolic extract; $\mathrm{W}=$ aqueous extract; $\mathrm{Amp}=$ ampicillin $(10 \mu \mathrm{g}) ; \mathrm{Chl}=$ chloramphenicol $(10 \mu \mathrm{g}) ; \mathrm{NC}$ = negative control. All assays were completed three times, each with internal triplicates $(n=9)$ and the results are expressed as mean zones of inhibition $(\mathrm{mm}) \pm$ SEM.

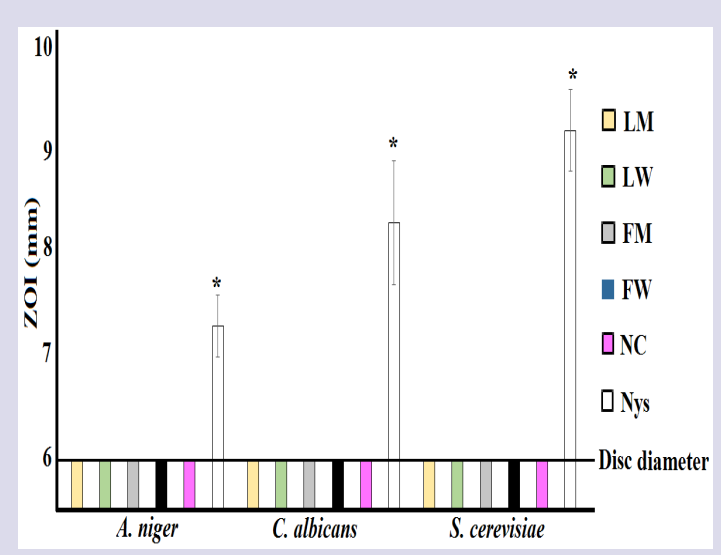

Figure 4: Growth inhibitory activity of $E$. grandis leaf extracts and reference antibiotics against fungal species measured as ZOIs $(\mathrm{mm}) \pm \mathrm{SEM}$. L $=$ leaf; $\mathrm{F}=$ fruit; $\mathrm{M}=$ methanolic extract; $\mathrm{W}=$ aqueous extract; $\mathrm{Nys}=\mathrm{Ny}-$ statin $(100 \mu \mathrm{g}) ; \mathrm{NC}=$ negative control. All assays were completed three times, each with internal triplicates $(n=9)$ and the results are expressed as mean zones of inhibition $(\mathrm{mm}) \pm \mathrm{SEM}$.

\section{DISCUSSION}

Due to recent increases in bacterial resistance to many antibiotics, the development of new antibiotic chemotherapies is a high priority for medical science. ${ }^{17,18}$ A concurrent decrease in the discovery of new antibiotic medicines by conventional strategies has increased interest in re-evaluating medicinal plants for new antibiotic chemotherapies. ${ }^{40}$ Whilst we were unable to find reports of the traditional use of E. grandis medicinally, it is taxonomically related to other Eucalyptus spp. with extensive therapeutic uses. Indeed, Lassak and McCarthy ${ }^{26}$ have recorded the use of Eucalyptus acmenoides, Eucalyptus camaldulensis, Eucalyptus creba, Eucalyptus haemastoma, Eucalyptus macrohyncha, Eucalyptus mi- 


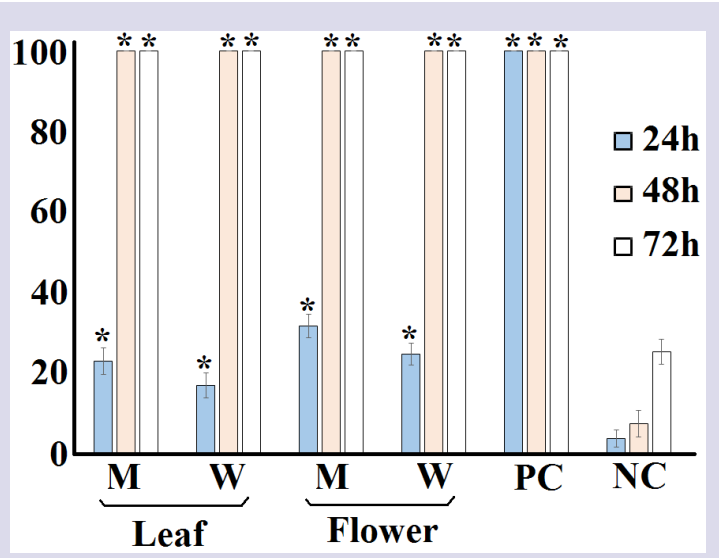

Figure 5: The lethality of the $E$. grandis leaf and flower extracts, potassium dichromate control (PC; $1000 \mu \mathrm{g} / \mathrm{mL}$ ) and seawater negative control (NC) following 24,48 and $72 \mathrm{hr}$ of exposure. $\mathrm{M}=$ methamolic extract; $\mathrm{W}$ $=$ aqueous extract. All bioassays were performed three times in triplicate $(n=9)$ and are expressed as mean \pm SEM. * indicates results that are significantly different to the untreated (seawater) control at the equivalent exposure time $(P<0.01)$ crocorys, Eucalyptus pilularis, Eucalyptus racemose, Eucalyptus resinifera, Eucalyptus saligna, Eucalyptus siderophloia, Eucalyptus tereticornis and Eucalyptus tetrodonta for the treatment of diarrhoea and dysentery. Much these diseases are caused by bacterial pathogens, including many of the pathogens tested in this study. Eucalyptus microtheca, Eucalyptus miniata and E. tetrodonta were also listed as useful against skin infections, whilst Eucalyptus globus, E. haemastoma, E. miniata, Eucalyptus oleosa, Eucalyptus pruinosa and E. tetrodonta are listed as being traditionally used to treat wound infections and as general bacteriocides. As this is perhaps the most extensive ethnobotanical examination of the ethnobotanical usage of Australian plants, the lack of recording of therapeutic usage of E. grandis is noteworthy and is consistent with our findings in this study. The antibacterial activity of many Eucalyptus spp. has been examined in laboratory studies and in many cases their activity has been verified. For example, potent growth inhibitory activity has been reported for Eucalyptus olida, Eucalyptus staigeriana, Eucalyptus dives ${ }^{41}$ Eucalyptus globus and Eucalyptus camaldulensis ${ }^{42}$ against multiple bacterial species. All of these studies have tested the bioactivity of essential oils prepared from the leaves of these species and the antibacterial activity of solvent extractions have been less extensively explored. Eucalyptus baileyana and Eucalyptus major methanolic and aqueous extracts have previously been reported to have potent antibacterial activity against a similar panel of

Table 1: The mass of dried extracted material, the concentration after resuspension in deionised water and qualitative phytochemical screenings of the $E$. grandis leaf and flower extracts.

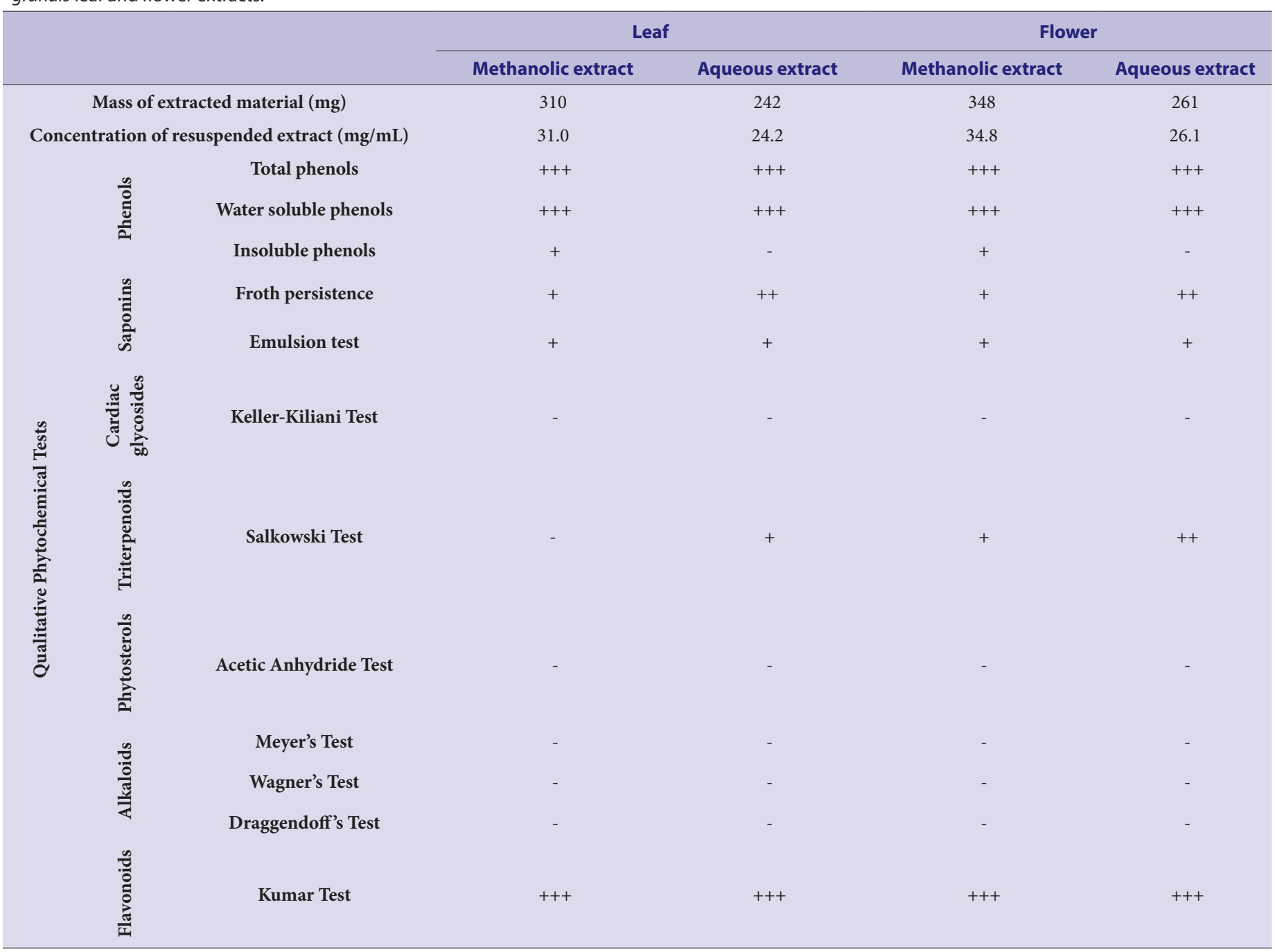




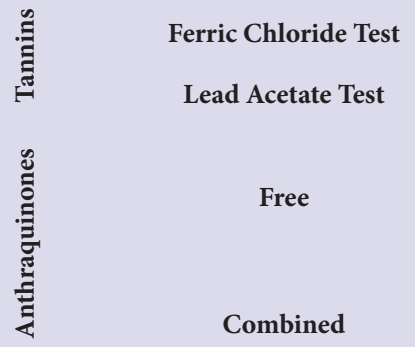

+++ indicates a large response; ++ indicates a moderate response; + indicates a minor response; - indicates no response in the assay.

bacteria to those tested in our study. ${ }^{27}$ Similarly, E. globus, E. maculata and Eucalyptus viminalis strongly inhibit the growth of the gram positive bacteria S. aureus, B. cereus, E. faecalis, Alicyclobacillus acidoterrestris and Propionibacterium acnes, but are relatively ineffective against gram negative bacteria. ${ }^{43}$ Interestingly, several recent studies have reported that the antibacterial activity of some Eucalyptus spp. may require the action of endophytic fungi associated with the leaves. ${ }^{44,45}$ It is possible that the E. grandis leaves examined in our study may not harbour these endophytes and this may result in the lack of activity seen in this study. Future studies are required to identify which (if any) fungal endophytes are associated with E. grandis leaves.

A single assay technique was used to screen for antibacterial activity in this study (as well as in the previous studies examining the antibacterial activity of this species). We chose to use the disc diffusion assay as it is a rapid method and it has previously been widely utilised in other studies. Therefore, comparisons between studies are relatively simple. However, as the disc diffusion method is reliant on the diffusion of a molecule through the aqueous environment of an agar gel, this assay may be affected by the solubility of the extract compounds in the aqueous environment. Polar compounds that are highly soluble in water would be expected to diffuse easily in the gel, whereas less soluble compounds would not diffuse as readily and thus be concentrated around the disc. Diffusion of molecules within an agar gel is also affected by the size of the molecules. The movement of large, complex phytochemicals (e.g. triterpenoids) through agar gels by diffusion would also be retarded and may provide a false idea of the efficacy of an extract. As many triterpenoids have well described antibiotic properties, screening for growth inhibition using agar diffusion techniques may give a fallacious view of its inhibitory potential. For this reason, whilst this is a handy assay for screening aqueous extracts, this technique may not be ideal for nonpolar compounds. For examining nonpolar mixtures, other techniques such as liquid dilution assays may be preferred. As Eucalyptus spp. are known to contain nonpolar terpenoid components, ${ }^{29}$ their activity may have been significantly underestimated. Liquid dilution studies may have been better suited to screen E. grandis extracts for activity and future studies will use these techniques to re-examine the extracts for antibacterial activity. The findings reported here also indicate that the extracts examined were non-toxic $\left(24 \mathrm{hr} \mathrm{LC}_{50}>1000 \mu \mathrm{g} / \mathrm{mL}\right.$ ) in the Artemia nauplii bioassay. Whilst toxicity was assessed in this study with the test organism $A$. franciscana, toxicity towards $A$. franciscana has previously been shown to correlate well with toxicity towards human cells for many toxins. ${ }^{39}$ However, further studies are required to determine whether this is also true for the E. grandis leaf extracts examined in these studies.

\section{CONCLUSION}

Methanolic and aqueous E. grandis leaf and flower extracts displayed no antibacterial activity in the disc diffusion assay against panels of human pathogenic bacteria and fungi, despite their close taxonomic relationship with other Eucalyptus spp. with well-known antibacterial properties. The extracts were nontoxic towards Artemia nauplii.

\section{ACKNOWLEDGEMENT}

The authors are grateful to Michelle Mendell and Jane Gifkins of Griffith University for providing the clinical bacterial and fungal strains used in this study. Financial support for this work was provided by the Environmental Futures Research Institute, Griffith University, Australia.

\section{CONFLICT OF INTEREST}

The authors report no conflicts of interest.

\section{ABBREVIATIONS}

DMSO: Dimethyl sulfoxide; $\mathbf{L C}_{50}$ : The concentration required to achieve $50 \%$ mortality; MIC: Minimum inhibitory concentration; ZOI: Zone of inhibition.

\section{REFERENCES}

1. Kamboj VP. Herbal medicine. Curr Sci. 2000;78(1):35-9.

2. Hostettmann K, Hamburger M. Search for new lead compounds of natural origin. In Perspectives in Medical Chemistry. Verlag Helvitica Acta, Basel. 1993.

3. Wright MH, Sirdaarta J, White A, et al. GC-MS headspace analysis of Terminalia ferdinandiana fruit and leaf extracts which inhibit Bacillus anthracis growth. Pharmacog J. 2017;9(1):73-82. DOI: 10.5530/pj.2017.1.14

4. Mpala LN, Chikowe GR, Cock IE. Growth inhibitory properties of extracts prepared from selected Leptospermum and Melaleuca species against a panel of pathogenic bacteria. Pharmacog Commn. 2016;6(4):215-24. DOI: 10.5530/ pc.2016.4.4

5. Omer E, Elshamy Al, Nassar M, et al. Plantago squarrosa Murray extracts inhibit the growth of some bacterial triggers of autoimmune diseases: GC-MS analysis of an inhibitory extract. Inflammopharmacol. 2018.. DOI: 10.1007/ s10787-018-0547-0

6. Newman DJ, Cragg GM, Snader KM. The influence of natural products on drug discovery. Nat Prod Rep. 2000;17(3):215-34.

7. Gaillot C, Sirdaarta J, Cock IE. Examination of the antimicrobial and anticancer properties of mangosteen. Acta Horticulturae. 2016;1106:231-8.

8. Wright $\mathrm{MH}$, Greene AC, Cock IE. Investigating the pharmacognostic potential of Indian Terminalia spp. in the treatment and prevention of yersiniosis. Pharmacog Commn. 2017;7(3):108-13. DOI: 10.5530/pc.2017.3.16

9. Gilani AH, Atta-ur-Rahman. Trends in ethnopharmacology. J Ethnopharmacol. 2005;100(1-2):43-9.

10. Hübsch Z, Zyl RLV, Cock IE, et al. Interactive antimicrobial and toxicity profiles of conventional antimicrobials with Southern African medicinal plants. South African Journal of Botany. 2014;93:185-97. DOI: 10.1016/j.sajb.2014.04.005

11. Cock IE, Vuuren VSF. Anti-Proteus activity of some South African medicinal plants: Their potential for the treatment and prevention of rheumatoid arthritis. Inflammopharmacol. 2014;22(1):23-36. DOI 10.1007/s10787-013-0179-3.

12. Omer E, Elshamy A, El Gendy AN, et al. Cakile maritima Scop. Extracts inhibit the growth of some bacterial triggers of autoimmune diseases: GC-MS analysis of an inhibitory extract. Pharmacog J. 2016;8(4):361-74. DOI: 10.5530/ pj.2016.4.9

13. Biggs I, Sirdaarta J, White A, et al. GC-MS analysis of Commiphora molmol oleo-resin extracts which inhibit the growth of bacterial triggers of selected autoimmune diseases. Pharmacog J. 2016;8(3):191-202. DOI: 10.5530/ pj.2016.3.4 
14. Biggs I, Sirdaarta J, White A, et al. GC-MS analysis of frankincense extracts which inhibit the growth of bacterial triggers of selected autoimmune diseases. Pharmacog Commn. 2016;6(1):10-22. DOI: 10.5530/pc.2016.1.3

15. Mohanty S, Cock IE. Evaluation of the antibacterial activity and toxicity of Myrciaria caulifloria methanolic leaf and fruit extracts. Int J Microbiol. 2009;7(2).

16. Cock IE. Medicinal and aromatic plants - Australia. In Ethnopharmacology, Encyclopedia of Life Support Systems (EOLSS): Developed under the auspices of UNESCO. Oxford, UK: EOLSS Publishers. 2011. Available from: http://www. eolss.net.

17. Cheesman MJ, Ilanko A, Blonk B, et al. Developing new antimicrobial therapies: Are synergistic combinations of plant extracts/compounds with conventional antibiotics the solution?. Pharmacog Rev. 2017;11(22):57-72. DOI: 10.4103/ phrev.phrev_21_17

18. WHO. Antimicrobial Resistance. World Health Organization. 2016. Available from: http://www.who.int/mediacentre/factsheets/fs194/en/. [Cited on 2017 May 10].

19. Sirdaarta J, Matthews B, Cock IE. Kakadu plum fruit extracts inhibit the growth of the bacterial triggers of rheumatoid arthritis: Identification of stilbene and tannin components. J Funct Food. 2015;17:610-20. DOI: 10.1016/j.jff.2015.06.019

20. Ilanko A, Cock IE. The interactive antimicrobial activity of conventional antibiotics and Petalostigma spp. Extracts against bacterial triggers of some autoimmune inflammatory diseases. Pharmacog J. 2019;11(2):292-309.

21. Winnett $\mathrm{V}$, Boyer $\mathrm{H}$, Sirdaarta J, et al. The potential of Tasmannia lanceolata as a natural preservative and medicinal agent: Antimicrobial activity and toxicity. Pharmacogn Commn. 2014;4(1):42-52. DOI: 10.5530/pc.2014.1.7

22. Cock IE. Antimicrobial activity of Callistemon citrinus and Callistemon salignus methanolic extracts. Pharmacog Commn. 2012;2(3):50-7. DOI: 10.5530/ pc.2012.3.11

23. Wright $\mathrm{MH}$, Lee CJ, Pollock CE, et al. Growth inhibitory activity of selected high antioxidant Australian Syzygium species against the food poisoning and tissue necrotic pathogen Clostridium perfringens. Pharmacog Commn. 2016;6(2):939. DOI: $10.5530 /$ pc. 2016.2.7

24. Wright $\mathrm{MH}$, Shalom J, Matthews B, et al. Terminalia ferdinandiana Exell. extracts inhibit Shewanella spp. growth and prevent fish spoilage. Food Microbiol. 2019;78:114-22. DOI:P 10.1016/j.fm.2018.10.006

25. Brooker MI. A new classification of the genus Eucalyptus L'Her. (Myrtaceae). Australian Systematic Botany. 2000;13(1):79-148.

26. Lassak EV, McCarthy TM. Australian medicinal plants. A complete guide tom identification and usage. Reed New Holland Publishers Sydney Australia. 2011.

27. Cock IE. Antimicrobial activity of Eucalyptus major and Eucalyptus baileyana methanolic extracts. Int J Microbiol. 2009;6(1):31.

28. Soyingbe OS, Oyedeji A, Basson AK, et al. The essential oil of Eucalyptus grandis W. Hill ex Maiden inhibits microbial growth by inducing membrane damage. Chinese Medicine. 2013;4(01):7.

29. Santos SA, Vilela C, Domingues RM, Oliveira CS, et al. Secondary metabolites from Eucalyptus grandis wood cultivated in Portugal, Brazil and South Africa. Industrial Crops and Products. 2017;95:357-64

30. Cock IE. The phytochemistry and chemotherapeutic potential of Tasmannia lanceolata (Tasmanian pepper): A review. Pharmacog Commn. 2013;3(4):13-25. DOI: $10.5530 /$ pc.2013.4.3

31. Hart C, Ilanko P, Sirdaarta J, et al. Tasmannia stipitata as a functional food/ natural preservative: Antimicrobial cctivity and toxicity. Pharmacog Commn. 2014;4(4):33-47. DOI: 10.5530/pc.2014.4.4

32. Winnett $V$, Sirdaarta J, White A, et al. Inhibition of Klebsiella pneumonia growth by selected Australian plants: Natural approaches for the prevention and management of ankylosing spondylitis. Inflammopharmacol. 2017:25(2):22335. DOI: 10.1007/s10787-017-0328-1

33. Wright $\mathrm{MH}$, Matthews $\mathrm{B}$, Arnold MSJ, et al. The prevention of fish spoilage by high antioxidant Australian culinary plants: Shewanella putrefaciens growth inhibition. Int J Food Sci Tech. 2016;51(3):801-13. DOI: 10.1111/ijfs.13026

34. Mpala L, Chikowe G, Cock IE. No evidence of antiseptic properties and low toxicity of selected Aloe species. J Pharmaceut Neg Res. 2010;1(1):10-6.

35. Lee CJ, Wright MH, Arnold MSJ, et al. Inhibition of Streptococcus pyogenes growth by native Australian plants: New approaches towards the management of impetigo, pharyngitis and rheumatic heart disease. Pharmacog Commn. 2016;6(3):164-73

36. Wright MH, Arnold MSJ, Lee CJ, et al. Qualitative phytochemical analysis and antibacterial activity evaluation of Indian Terminalia spp. against the pharyngitis causing pathogen Streptococcus pyogenes. Pharmacog Commn. 2016;6(2):8592

37. Cock IE, Winnett V, Sirdaarta J, et al. The potential of selected Australian medicinal plants with anti-Proteus activity for the treatment and prevention of rheumatoid arthritis. Pharmacog Mag. 2015;11(Suppl 1): S190-208.

38. Hart C, Cock IE. An examination of the antimicrobial and anticancer properties of Garcinia cambogia fruit pericarp extracts. BEMS Reports. 2016;2(1):23-6.

39. Cock IE, Ruebhart DR. Comparison of the brine shrimp nauplii bioassay and the ToxScreen-II test for the detection of toxicity associated with Aloe vera (Aloe barbadensis Miller) leaf extract. Pharmacog Res. 2009;1(2):98-101.

40. Aiyegoro OA, Okoh Al. Use of bioactive plant products in combination with standard antibiotics: Implications in antimicrobial chemotherapy. J Med Plant Res. 2009;3(13):1147-52.

41. Gilles M, Zhao J, An M, Agboola S. Chemical composition and antimicrobial properties of essential oils of three Australian Eucalyptus species. Food Chemistry. 2010;119(2):731-7.

42. Ghalem BR, Mohamed B. Antibacterial activity of leaf essential oils of Eucalyptus globulus and Eucalyptus camaldulensis. African Journal of Pharmacy and Pharmacology. 2008;2(10):211-5.

43. Takahashi T, Kokubo R, Sakaino M. Antimicrobial activities of eucalyptus leaf extracts and flavonoids from Eucalyptus maculata. Letters in Applied Microbiology. 2004;39(1):60-4

44. Kharwar RN, Gond SK, Kumar A, Mishra A. A comparative study of endophytic and epiphytic fungal association with leaf of Eucalyptus citriodora Hook. and their antimicrobial activity. World Journal of Microbiology and Biotechnology. 2010;26(11):1941-8.

45. Sathish L, Pavithra N, Ananda K. Antimicrobial activity and biodegrading enzymes of endophytic fungi from Eucalyptus. International Journal of Pharmaceutical Sciences and Research. 2012;3(8):2574.
PICTORIAL ABSTRACT

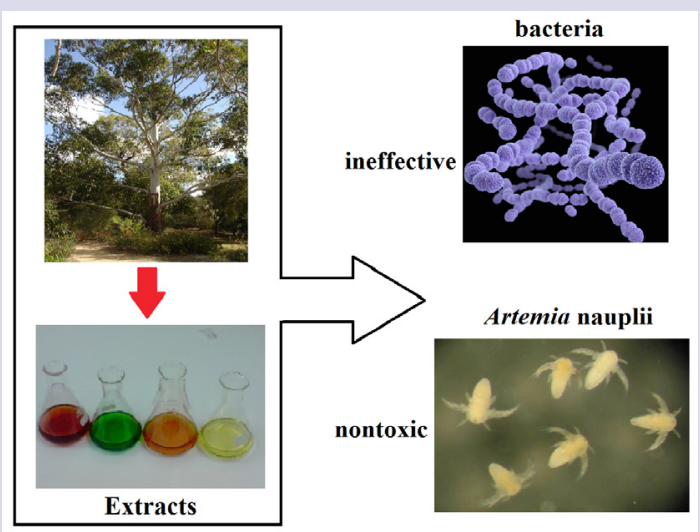

\section{SUMMARY}

- $\quad$ E. grandis leaf and flower extracts were screened for the ability to block the growth of a panel of human bacterial pathogens.

- No inhibitory activity was evident against any of the bacterial species tested.

- $\quad$ Toxicity of the E. grandis extracts was determined using the Artemia nauplii toxicity bioassay. 


\section{ABOUT AUTHORS}

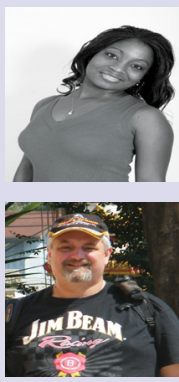

Ms Lindiwe Mpala, completed at BSc at Griffith University in life sciences. Following graduation, she undertook a research project in Dr lan Cock's laboratory in the School of Natural Sciences at Griffith University. The project examined the growth inhibitory properties of a variety of Australian native plants against an extensive panel of bacterial pathogens.

Dr. Ian Cock leads a research team in the Environmental Futures Research Institute and the School of Natural Sciences at Griffith University, Australia. His research involves bioactivity and phytochemical studies into a variety of plant species of both Australian and international origin, including Aloe vera, South Asian and South American tropical fruits, as well as Australia plants including Scaevola spinescens, Pittosporum phylliraeoides, Terminalia ferdinandiana (Kakadu plum), Australian Acacias, Syzygiums, Petalostigmas and Xanthorrhoea johnsonii (grass trees). This range of projects has resulted in nearly 200 publications in a variety of peer reviewed journals. 